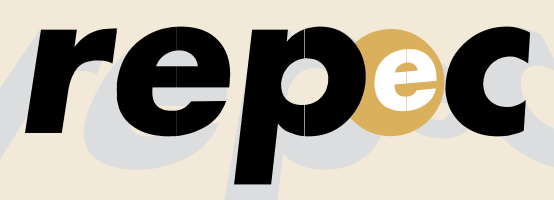

REPeC, Brasília, v. 12, n. 2, art. 1, p. 153-168, abr.jun. 2018 Disponivel online em www.repec.org.br D0l: http://dx.doi.org/10.17524/repec.v12i2.1664
Revista de Educação e Pesquisa em Contabilidade Journal of Education and Research in Accounting

Periódico Trimestral, digital e gratuito publicado pela Academia Brasileira de Ciências Contábeis

ISSN 1981-8610

\title{
O Conselho de Administração ou a Carne é Fraca? O dilema da BRF S.A.
}

\author{
Resumo \\ Objetivo e método:Este caso para ensino retrata o problema \\ de Governança Corporativa (GC) da BRF S.A. deflagrado \\ pela Operação Carne Fraca da Polícia Federal. Oobjetivo é \\ estimular discussões sobre a efetividade dos conselhos de \\ administração como mecanismos de GC e no processo decisório \\ de investimento em ações. O caso pode ser aplicado em cursos \\ de pós-graduação, especialmente em disciplinas cujos conteúdos \\ se relacionem com Mercado de Capitais, Finanças, Estratégia \\ Empresarial e GC, além de cursos de graduação em disciplinas \\ correlatas. Os dados sobre a origem e evolução histórica da \\ empresa, bem como sobre os personagens envolvidos no caso \\ foram obtidas por meio de sites, matérias de revistas e website da \\ companhia. As informações coletadas e transcritas não sofreram \\ adaptações.O roteiro e os acontecimentos são eventos reais. A \\ situação do investidor é fictícia. \\ Resultados e contribuições: O caso propõe o exercício da \\ tomada de decisão, embasada em dois pontos de vista:pelo lado \\ da empresa, analisa-se o Conselho de Administração como \\ mecanismo interno de GC; e no ponto de vista do acionista, \\ um investidor que confiou suas reservas de capital àquela \\ companhia.O caso permite a análise da efetividade do conselho \\ de administração como mecanismo interno de governança, a \\ assimetria de informações, conflitos de interesse e a estrutura de \\ propriedade. \\ Palavras-chave: Conselho de Administração; Shareholders; \\ Governança Corporativa.
}

\section{Raul Beal Partyka}

Mestrando em Administração na Universidade do Vale do Itajaí (Univali). Contato: Rua João Coan, 400, Sala 408, Universitários, Biguaçu (SC), CEP: 88161-064. E-mail: raul@edu.univali.br

\section{Jeferson Lana}

Doutor em Administração de Empresas pela FGV-EAESP e Professor na Universidade do Vale do Itajaí (Univali). Contato: Rua João Coan, 400, Sala 408, Universitários, Biguaçu (SC), CEP: 88161-064.

E-mail: jlana@univali.br

\section{Anete Alberton}

Doutora em Engenharia de Produção pela Universidade Federal de Santa Catarina (UFSC) e Professora na Universidade do Vale do Itajaí (Univali). Contato: Rua João Coan, 400, Sala 408, Universitários, Biguaçu (SC), CEP: 88161-064.

E-mail: anete@univali.br 


\section{Introdução}

Dentro do mercado de capitais, sempre há, ao menos, dois pontos de vista: o da empresa e o do investidor. Pela ótica da empresa, está a BRF, empresa multinacional do setor de alimentos, uma das maiores produtoras mundiais de proteína in natura e congelados. A organização resultou da fusão de duas empresas brasileiras, Perdigão e Sadia, que foi anunciada em 2009 e concluída em 2012. Ambas as companhias que a compuseram eram negócios familiares. A Perdigão nasceu em 1934, na cidade de Videira (SC), e a Sadia em 1944, em Concórdia (SC). Ambas tinham valores berço: o negócio familiar, o respeito ao trabalho, o cuidado com a terra e a valorização da técnica. Cresceram e se expandiram, tornando-se grandes atuantes do mercado de alimentos no Brasil e, posteriormente, no exterior. Seus produtos incluem frango e peru, carnes especiais, alimentos processados congelados, pratos prontos congelados, porções, produtos fatiados, margarina, sobremesas especiais, sanduíches, maionese e ração animal. Os produtos chegam a mais de 150 países, nos cinco continentes, através de algumas de suas marcas consagradas, como Sadia, Perdigão, Qualy, Dánica e Paty. Possui capital aberto desde 1980,em que, atualmente integra o Novo Mercado da B3 (BRFS3), Bolsa de Valores do Brasil, e também tem seus papéis negociados na NYSE (BRFS), Bolsa de Valores de Nova Iorque, Estados Unidos. O faturamento em 2016 teve um aumento de 4,9\% com relação a 2015, passando de 37.23 para 39.06 bilhões de reais, em que foram comercializados mais de quatro milhões de toneladas de alimentos.

A companhia possui mais de 100 mil funcionários, distribuídos por mais de 50 fábricas em oito países. Como representante maior está Abilio Diniz, presidente do Conselho de Administração (CA). Abílio Diniz é administrador por formação, acostumado a lidar com situações complexas nas mais variadas arenas executivas; já liderou outras empresas e também teve passagem pelo Governo federal, tendo sido membro, por mais de dez anos, do Conselho Monetário Nacional, órgão máximo do Sistema Financeiro Nacional. Abílio aprendeu muito com seu pai, que tinha o mesmo ofício. Ainda jovem, acompanhou seu pai chefiando uma empresa cuja fundação se deu na década de 1970 e que se tornou nacionalmente conhecida como Pão de Açúcar.

A gestora de fundos Tarpon tornou-se a maior sócia privada da BRF. Dois sócios da Tarpon, Pedro Faria e Zeca Magalhães, eram conselheiros da empresa, mas precisavam de um nome novo para convencer a maioria do conselho e dos acionistas a mudarem a gestão. O empresário Abílio Diniz embarcou no projeto quando comprou cerca de $3 \%$ das ações da BRF e, com o apoio da Previ, fundo de pensão dos funcionários do Banco do Brasil, assumiu a Presidência do Conselho, substituindo Nildemar Secches em 2013 (Filgueiras, 2017, p. 81).

O Conselho de Administração da BRF é composto de nove membros, sendo seis deles independentes. O presidente do Conselho não exerce funções executivas. Está definido no Estatuto Social que o presidente deve ter reputação ilibada, não ocupar cargos em concorrentes nem representar interesses conflitantes.

O chiefexecutiveofficer (CEO), Pedro de Andrade Faria, é um especialista financeiro e sócio da maior acionista privada da BRF, a Tarpon:

Aos 40 anos, Pedro Faria assumiu o comando da BRF no dia 2 de janeiro de 2015. Empolgado com o sucesso do primeiro ano da nova gestão, Faria começou a segunda fase da reestruturação da BRF - um processo que hoje é conhecido internamente como "tarponização-ambevização" da companhia (Filgueiras, 2017, p. 82).

Já pelo ponto de vista do acionista, encontra-se Marcelo, um dos milhares de investidores da BRF no Brasil e no mundo. Estudante brasileiro e muito curioso pelo mercado de capitais, Marcelo encontrou na BRF S.A. a esperança de multiplicar seu dinheiro. Entre 2006 e 2015, as ações da BRF chegaram a subir de 10 reais para 70 reais. Marcelo analisou as informações econômico-financeiras da empresa e descobriu que, caso tivesse investido todo seu dinheiro em ações da BRF naquele período, hoje seria um milionário. Com esta conclusão, investiu assim, em fevereiro de 2017, todas as suas reservas de capital nesta companhia. Pensava que, talvez, poderia até se aposentar, por que não? Depois de muito analisar, passou a confiar na empresa e em toda sua estrutura. 
Mas nem tudo são flores. Naquela sexta-feira, 17 de março de 2017, um fato marcante abalaria os alicerces de governança da BRF e, por consequência, a rentabilidade dos investimentos de Marcelo. A notícia estava em todo lugar: a Polícia Federal havia descoberto um esquema de pagamento de suborno defuncionários da BRF a fiscais do Ministério da Agricultura, Pecuária e Abastecimento (Mapa). O motivo dessa corrupção era evitar a fiscalização efetiva em uma das fábricas da companhia e assim mantê-la em funcionamento.

De um lado, o presidente do Conselho de Administração da BRF, que deveria gerenciar e monitorar a empresa em operações constantes e minuciosas, buscando maximizar a riqueza dos acionistas, tinha mais de um entrave a ser resolvido, a partir do desconhecimento da prática ilícita e do envolvimento de funcionários e diretores do alto escalão. Além disso, havia a necessidade de investigação dos fatos pelo Conselho de Administração. Decisões deveriam ser tomadas tendo em vista a melhor resolução do problema, de forma interna e também para diminuir a repercussão externa.

Por outro lado, havia Marcelo, um dos acionistas, que apostou seu patrimônio em uma das empresas com melhor estrutura de governança no Brasil, até então. E agora? Enquanto ambos buscam soluções, ou ao menos entender o problema, as ações da empresa derretem na Bolsa de Valores. O conselho de administração seria efetivo em representar os interesses dos acionistas, no seu papel de supervisão e gerenciamento das estratégias e operações, e estancariaessa catástrofe? E Marcelo, deveria manter suas ações na BRF ou retirá-las, para mitigar o risco devido à assimetria de informação?

\section{Operação "Carne Fraca": corrupção envolvendo a BRF}

A Polícia Federal (PF) tinha programado um 17 de março especial. Nessa data, que marcou o aniversário de três anos das investigações da Lava-Jato, a PF deflagrou sua maior operação, batizada de "Carne Fraca"(Filgueiras, 2017, p. 88).

A PF expôs a corrupção que acontecia entre empresa e órgão federal, como resultado de dois anos de investigação, que envolveu mais de 1,1 mil policiais. Quando a instituição “[...] convocou uma coletiva de imprensa [...] para mostrar o inquérito de 353 páginas que resultou na Operação Carne Fraca, veio à tona uma situação que pode ter surpreendido a maioria dos brasileiros. Mas não os auditores fiscais federais agropecuários" (Caetano, 2017, p. 32).

A ação da PF desfez um esquema de corrupção radicado em pelo menos três superintendências estaduais do Ministério da Agricultura, a do Paraná, a de Minas Gerais e a de Goiás. Em troca de propina, fiscais, veterinários e chefes do Ministério nesses estados emitiam falsos certificados de garantia de qualidade para frigoríficos que, munidos desses certificados, não se preocupavam em atender às exigências sanitárias mínimas estabelecidas por lei (Campbell, 2017, p. 50).

Nesse momento, o presidente do Conselho da BRF precisou reunir todos os executivos, para confirmar que não era somente ele que desconhecia essa prática diante da sua supervisão. e também para conter o mais rápido possível os efeitos negativos recaídos sobre a imagem da empresa.

\section{A denúncia de corrupção}

A investigação apontou que os frigoríficos exerciam influência direta sobre o Ministério da Agricultura para escolher os agentes que iriam efetuar as fiscalizações na empresa, por meio do pagamento de vantagens indevidas (Folha, 2017).

Ainda de acordo com a PF, funcionários da BRF tinham livre trânsito no Ministério da Agricultura, para acessar o sistema de fiscalização usado pelos auditores, com aceitação do ex-superintendente do Ministério da Agricultura do Paraná, Daniel Gonçalves Filho, apontado como o chefe do esquema (Campbell, 2017, p. 50).Um gerente e um diretor da empresa foram presos pela PF e houve buscas na casa do vice-presidente de integridade corporativa (Filgueiras, 2017, 79). 
Em meio à crise econômica e política, perder dinheiro é como acelerar o carro em direção ao abismo. Mas o que piorou toda a história foi a combinação da operação policial com a expectativa da atual diretoria, criada ao assumir o comando há quatro anos.

Uma conversa grampeada pela PF revelou que o agente do Ministério da Agricultura responsável pela fiscalização no local afirmou que iria "matar no peito" a notificação da suspensão da planta e que não avisaria Brasília (Uol Economia, 2017).

Para a PF, uma conversa entre os dois diretores da BRF mostrou que o médico-veterinário Dinis Lourenço da Silva, chefe do Serviço de Inspeção de Produtos de Origem Animal, em Goiás, estava pedindo uma propina de 300 mil reais para acobertar algumas irregularidades na unidade da BRF, em Mineiros, no interior do estado. Em troca do pagamento, o veterinário voltaria à unidade de Mineiros para refazer a vistoria e - surpresa! - constataria que, daquela vez, tudo estava em ordem (Bonin, 2017, p. 55).

\section{Reunião do Conselho de Administração}

A menos de duas horas depois de a Polícia Federal deflagrar a Operação Carne Fraca, na manhã da sexta-feira, 17 de março de 2017, os oito executivos do mais alto escalão da BRF já haviam se trancados na sala principal de reuniões, no escritório central da Companhia, em São Paulo. Entre eles estavam o CEO, Pedro Faria, e o presidente do conselho de Administração, Abílio Diniz. O objetivo era definir um plano de ação para estancar o sangramento público da reputação da empresa, acusada de praticar corrupção para ter seu processo de fiscalização sanitária afrouxado pelos agentes do Ministério da Agricultura (Cilo\&Drska, 2017, p. 42).

Todos falavam rápido. Os celulares não paravam de vibrar. A cada minuto ali, milhares de comentários negativos e piadas jocosas sobre a empresa eram publicados e inundavam as redes sociais (Cilo\&Drska, p. 42).Diante de tantas notícias e comentários se espalhando, demandava-seurgência na reação da companhia. Desta forma:

O senso de urgência, no caso da operação Carne Fraca, gerou resultado quase que imediato. Em pouco mais de 20 minutos, o maior plano de ação da história da BRF estava pronto. Antes mesmo de deixarem a sala, os executivos decidiram criar um comitê de gestão de crise. Convocaram os principais criativos da agência de publicidade DM9, os diretores da agência de relações públicas Loures Comunicação, dos três escritórios de advocacia que dão suporte jurídico à empresa, e chamaram, a toque de caixa, os mais experientes diretores $\mathrm{e}$ funcionários de alto escalão da BRF (Cilo\&Drska, 2017, pp. 42-44).

O ministro da Agricultura, Blairo Maggi, também preocupado com toda a repercussão, procurou a empresa para se informar sobre o tratamento que ela estava dando ao problema. Segundo matéria publicada na revista Globo Rural de 17 de Março de 2017, o ministro conversou com Pedro Faria e com Abílio Diniz e manifestou a eles sua preocupação com arepercussãodo assunto. Os executivos garantiram que havia procedimentos internos para tratar disso e que há quatro anos não tinham notícias desse tipo de desvio de conduta e iriam trabalhar em conjunto para esclarecer os fatos.

"Ninguém ali tinha noção da intensidade e do alcance daquela crise. Só sabíamos que tínhamos de agir de forma rápida e transparente", disse para Cilo \& Drska (2017, p.42) um executivo ligado à BRF, que acompanhou de perto os bastidores da reação.

Logo depois da criação do Comitê, a BRF divulgou uma página na internet -brf.com.br/portasabertas-, que continha uma carta de esclarecimento sobre o escândalo. Havia também uma equipe para responder aos comentários dos consumidores nas redes sociais, e uma estrutura foi montada para atender à imprensa brasileira e internacional. Sem perder tempo e de forma ininterrupta, os funcionários selecionados pela cúpula da BRF entravam em contato com fornecedores, clientes e investidores, a fim de colocar "panos quentes" sobre os fatos, para tentar apaziguar a situação (Cilo \& Drska, 2017, p. 44). 


\section{Um pequeno investidor}

Marcelo tem 26 anos e é aluno do MBA de Mercado de Capitais. O jovem vinha acompanhando há algum tempo as companhias listadas na Bolsa de Valores Brasileira (B3). Ele tinha muito interesse em empresas brasileiras, tanto que decidiu que deveria partir para investimentos mais lucrativos, já que possuía algum conhecimento sobre o tema e seus colegas já compravam e vendiam ações. Marcelo estava concluindo a sua especialização e seria uma boa hora para ele começar. Assim, passou alguns dias analisando o mercado, em busca de uma empresa em que pudesse investir seu capital.

O jovem chegou aos papéis da BRF com grande interesse pelo investimento, porque seu pai tinha trabalhado por mais de 30 anos na Perdigão (uma das empresas incorporadas na fusão que resultou na criação da BRF) até vir a se aposentar. Avaliou seus principais investidores, seus conselheiros, a formação e remuneração destes, e também a contribuição da companhia para o País,em valor econômico e social, para que ele se sentisse sócio de verdade.

No final de 2012, a BRF trocou de gestão. Os acionistas majoritários criticavam a morosidade da antiga administração. Um grupo de acionistas, liderado pela gestora Tarpon, juntou-se a Abílio Diniz para dar as cartas na BRF. Trocaram tudo, começando pela cúpula da companhia. Nildemar Secches deixou a presidência do Conselho, dando lugar a Diniz. As mudanças na diretoria vieram em seguida. A Tarpon e seu grupo criticavam o que consideravam lentidão da administração da BRF, considerando-auma gigante que poderia ser transformada em uma líder global. Investidores compraram a ideia de que as ações, na época ao redor dos 40reais, valeriam pelo menos 100 reais em quatro anos. Hojeas ações da BRF valem cerca de 35 reais, quase $20 \%$ menos, portanto, do que valiam quatro anos atrás (Filgueiras, 2017, pp. 78-79).

O Quadro 1 descreve o perfil dos conselheiros da BRF, representantes dos acionistas minoritários, analisados por Marcelo.

\begin{tabular}{ccc}
\hline Conselheiro & Função & Formação \\
\hline Abílio dos Santos Diniz & $\begin{array}{c}\text { Presidente do Conselho } \\
\text { (independente) }\end{array}$ & Administração de Empresas \\
\hline Renato Proença Lopes & Vice-Presidentedo Conselho & $\begin{array}{c}\text { Pós-graduação em Administração e MBA em Gestão } \\
\text { de Negócios de Atacado }\end{array}$ \\
\hline Henri Philippe Reichstuk & Membroefetivo (independente) & Pós-graduaçãoem Economia \\
\hline Luiz Fernando Furlan & Membroefetivo(independente) & EspecializaçãoemAdministraçãoFinanceira \\
\hline Manoel Cordeiro Silva Filho & Membroefetivo (independente) & $\begin{array}{c}\text { Pós-graduação em Engenharia Econômica e MBA em } \\
\text { Finanças }\end{array}$ \\
\hline Walter Fontana Filho & Membroefetivo (independente) & Pós-graduaçãoem Economia \\
\hline José Carlos Reis de & Conselheiroefetivo & Administração de Empresas \\
\hline Magalhães Neto & Conselheiroefetivo & MBA em Top Executives e em Finanças \\
\hline Aldemir Bendine & Conselheiroefetivo & Ph. D. em Engenharia \\
\hline Vicente Falconi Campos & Memolno
\end{tabular}

Quadro 1. Composição do Conselho de Administração da BRF em 22 de abril de 2017

Fonte: os autores, com base em Econoinfo e Website Relação com Investidores BRF, 2017.

Pedro Faria, o CEO, assumiu o comando da companhia no dia 2 de janeiro de 2015. Até então, ele tinha sido Diretor de Relações com Investidores da Tarpon. É formado em Administração de Empresas pela FGV-SP e cursou MBA pela Universidade de Chicago (EUA).Em 2016, a remuneração paga pela BRF a todos os membros do Conselho de Administração chegava a um valor superior a 7,5 milhões de reais.

A Tabela 1 mostra a divisão societária da BRF, ilustrando uma das fontes de pesquisa para definição do investimento de Marcelo, relacionada à dispersão ou concentração de propriedade. 
Tabela 1

Composição Acionária da BRF em 31/05/2017

\begin{tabular}{lcc}
\hline \multicolumn{1}{c}{ Acionista } & Qtde. de Ações ON & Ações ON (\%) \\
\hline Petros - Fundação Petrobras de Seguridade Social & 92.716 .266 & 11,41 \\
\hline Previ - Caixa Previdência Funcionários Banco do Brasil & 86.691 .252 & 10,67 \\
\hline Tarpon Gestora de Recursos S.A. & 69.131 .442 & 8,51 \\
\hline GIC Private Limited & 51.913 .800 & 6,39 \\
\hline BlackRock Inc. & 40.867 .404 & 5,03 \\
\hline Ações em Tesouraria & 13.468 .001 & 1,66 \\
\hline Outros & 457.684 .835 & 56,33 \\
\hline Total & 812.473 .000 & 100,00 \\
\hline
\end{tabular}

Fonte: os autores, com base em Econoinfo, 2017.

Marcelo pesquisou a fundo a BRF, todo seu histórico até a troca de sua gestão, o site de relação com os investidores ( $w w w$.brf-br.com/ri), demonstrativos financeiros, relatórios anuais e de sustentabilidade, os índices econômico-financeiros, a composição do conselho de administração e composição acionária. Além disso, pesquisou o estatuto, políticas e regimentos voltados para investidores da BRF, tal como as políticas de dividendos. Já se sentia um futuro investidor: "A companhia é uma das melhores em governança que eu analisei. Tem vários membros independentes no Conselho, assim como o presidente. Eles têm condições de tomar boas decisões de investimento, financiamentos e gestão, esperando sempre representar os direitos dos acionistas". Assim pensou Marcelo, após seus primeiros dias de apreciação.

A companhia foi a primeira empresa do setor de alimentos e bebidas a se enquadrar nas regras do Novo Mercado da B3, em 12 de abril de 2006, que é o segmento altamente diferenciado de governança da Bolsa. Mais uma informação que creditou a empresa perante os acionistas, indicando que ela segue um padrão de transparência e governança.

A empresa também é altamente regulada, até duplamente regulada, uma vez que suas ações são negociadas na Bolsa de Valores de São Paulo e na Bolsa de Nova York. Com a presença nos dois mercados, a Companhia obedece, em suas demonstrações financeiras, aos princípios internacionais de contabilidade (IFRS) e as determinações do Sistema de Controle Interno do Reporte Financeiro (SCIRF), baseados na Lei Sarbanes-Oxley (SOX).

Após horas de uma análise fundamentalista, Marcelo chegou à conclusão de que deveria investir na BRF. Definiu a empresa como um ótimo investimento, levou em conta principalmente o perfil de seus executivos, disponibilizados pela própria companhia. Em teoria, tratava-se de uma ótima equipe, bem remunerada, altamente assessorada. Marcelo investiu, então, em fevereiro de 2017, todas as suas reservas de capital, comprando ações da BRF. Conforme seu depoimento: "Confirmei muitas informações que me fizeram apostar na BRF como a melhor companhia para investir meu dinheiro. Há uma pequena porcentagem, entre 10 e $12 \%$ de ações concentradas em apenas um acionista. O perfil dos conselheiros é, na grande maioria, com alguma formação nas áreas de Administração, Finanças ou Economia. Nos últimos 10 anos o valor da ação da companhia deu um salto da casa dos 10 reais para 70 reais. Acredito que, com a nova gestão, esse patamar possa ser alcançado novamente."

Em certo momento,porém,entrouem jogo um problema que existe em diversos paísescomo algo endêmico:a corrupção. Nesse caso, na sociedade brasileira, em que se constata que, devido auma fraca ética social histórica, quanto mais burocracia, mais regras existem. Mais força tem aquele fiscal que cria dificuldades para vender facilidades a um funcionário que acha errado esse jeito normal de se operar no Brasil,mas talvez essa operação traga algum efeito educativo.

Contudo, conforme avaliação de Adeodato Volpi Netto, estrategista-chefe de mercado de capitais da Eleven Financial Research, para Gradilone (2017), o que assusta os investidores não é apenas o efeito imediato da Operação Carne Fraca sobre os resultados das empresas, mas seus desdobramentos. Antes da operação, a Eleven considerava os papéis da BRF uma das ações mais promissoras do setor. 
Dessa forma, atumultuada operação lançada pela PF, no dia 17 de março de 2017, prejudicou milhares de investidores. Os acionistas amargaram perdas de até $10 \%$ em poucos dias. O susto foi tão grande que afetou não apenas a BRF, mas também outras empresas do setor, que viram a queda de até $9 \%$ no valor de suas ações (Gradilone, 2017, p. 48).

Porém, após saber da notícia do caso de suborno, o que mais preocupou Marcelo não foi apenas o fato de estar tendo prejuízo com aquele investimento, mas também o fato de ver a proporção que tomou o caso de corrupção entre empresa e fiscalização. Ele ainda não tinha noção de quais seriam os efeitos desse fato sobre os resultados imediatos da empresa. Marcelo, porém, começava a perceber que o Conselho de Administração poderia ter falhado no exercício de suas funções, pois esse mecanismo de governança corporativo interno deve buscar a eficiência na monitoria da empresa em operações constantes de pente fino, buscando maximizar sempre a riqueza dos acionistas e ajudar os investidores a definirem as melhores empresas para investimento.

No dia 16 de março de 2017, um dia antes da divulgação da Operação Carne Fraca, uma ação BRFS3 fechou cotada em 40,01 reais. No dia 17, a ação já iniciou o pregão ao valor de 38,00 reais e, ao fim do dia, acumulou uma baixa de 7,30\% em 24 horas, fechando em 37,09 reais. Esse valor foi registrado pela primeira vez na história da companhia. Chegou à sua mínima no dia 22, ao valor de 35,58 reais. Nem o mais pessimista investidor estaria esperando tal acontecimento, ainda que considerasse $\mathrm{o}$ atual cenário nacional. Contudo, no dia 18 de abril de 2017, um mês e um dia após a deflagração da operação, uma ação BRFS3 fechou cotada a 40,62 reais (Figura 1), ultrapassando até mesmo o valor anterior ao do dia do anúncio da Operação Carne Fraca e também da sua divulgação intensiva pela mídia.

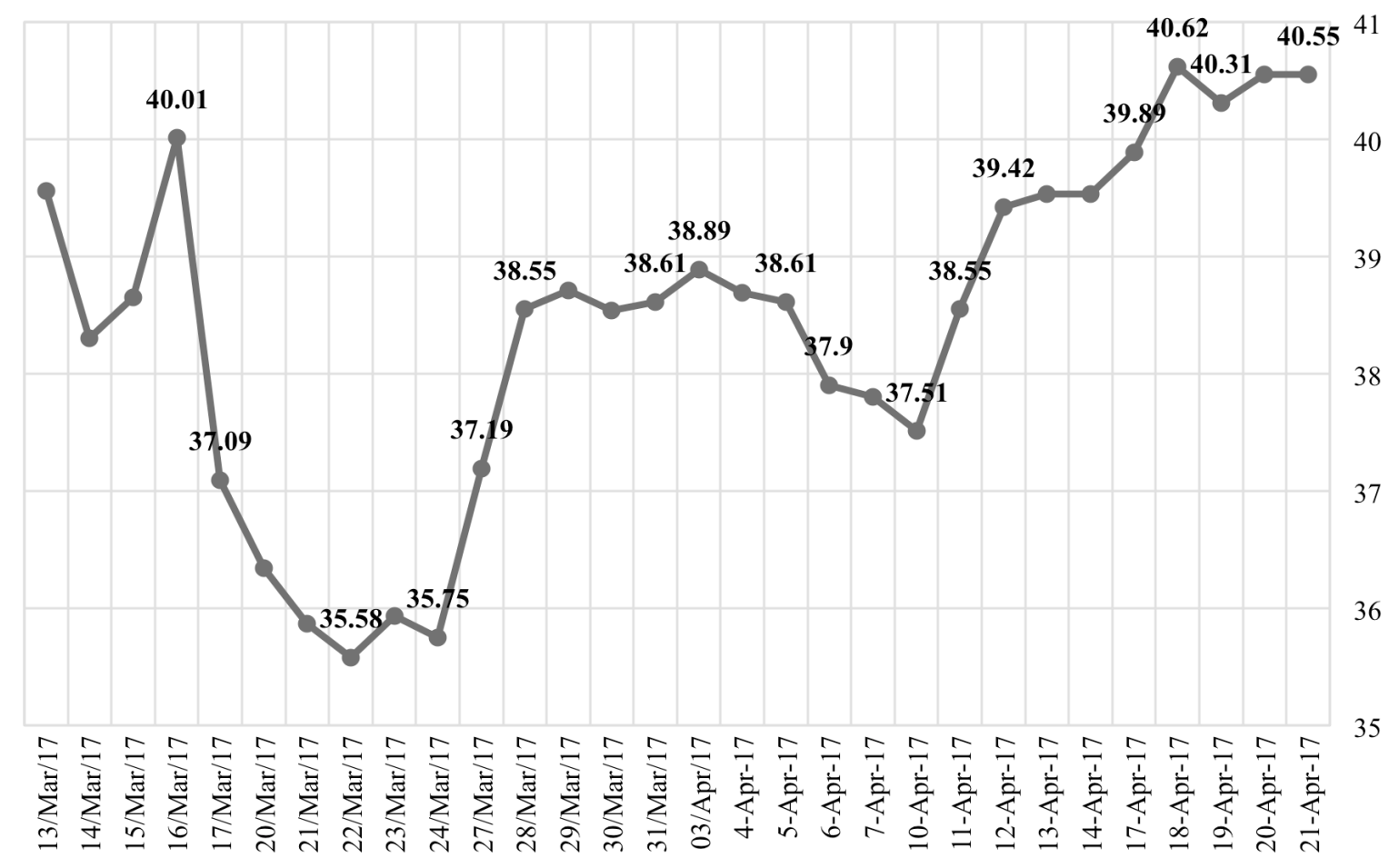

Figura 1. Cotações de fechamento da ação BRFS3 de 13 de março a 21 de abril de 2017

Fonte: elaborado pelos autores com base em ADVFN Brasil, 2017. 


\section{Coisa ruim não acontece só com os outros}

No Brasil, não é nenhuma novidade, e não é necessáriopensar muito para lembrar de outros casos de suborno, corrupção, entre outros desvios de conduta, em que não existe qualquer ato louvável. Nesse caso, o Conselho tinha mais de um entrave a ser resolvido, começando pelo desconhecimento da prática e do envolvimento de funcionários e diretores do alto escalão. Isso tudo e mais a necessidade de investigação pelo Conselho de Administração. Havia decisões a serem tomadas para a melhor resolução desses fatos, de forma interna e também para atenuar a repercussão dos fatores externos. Por outro lado, um pequeno acionista, que confiou suas reservas de capital a uma companhia, até então sem risco de perdas significativas, viu seu patrimônio ser drasticamente reduzido em questão de algumas horas.Sendo assim, quais mecanismos poderiam mitigar o conflito dos agentes? O Conselho de Administração teria sido efetivo em representar os interesses dos acionistas no seu papel de supervisão e gerenciamento das estratégias e operações? Marcelo deveria manter suas ações na BRF ou retirá-las, para mitigar seu risco devido à assimetria de informação?

\section{Notas de Ensino}

As Notas de Ensino são de acesso exclusivo aos docentes, de forma a direcionar os objetivos, estratégias metodológicas e avaliação do caso para ensino.

\subsection{Fontes de dados}

As fontes dos dados sobre a origem e evolução histórica da empresa, bem como sobre os personagens envolvidos no caso foram obtidas por meio de sites, matérias de revistas e website da companhia. $\mathrm{O}$ ponto de vista do acionista é fictício, criado por meio do personagem Marcelo. Os dados apresentados sobre a Operação Carne Fraca e seus desdobramentos são reais e foram obtidos de fontes secundárias, por meio de reportagens em revistas, páginas da internet, Políticas, Estatuto e Regimentos da Companhia (ADVFN Brasil, website B3, as revistas periódicas Carta Capital, Época Negócios, Uol Economia, Folha de São Paulo, EXAME, Isto é Dinheiro, VEJA, Dinheiro Rural, Globo Rural, os websites BRF e EconoInfo). O período da coleta de dados foi de 14 de março de 2017 até 29 de agosto de 2017. Primeiramente, foram catalogadas digitalmente todas as revistas e matérias jornalísticas que citassem a operação Carne Fraca. Após esse processo, capturou-se dessa amostra os trechos que compuseram o caso de ensino. As informações coletadas e transcritas não sofreram adaptações ou inclusões de enredo. $\mathrm{O}$ roteiro e acontecimentos são eventos reais.

\subsection{Objetivos educacionais}

O dilema da BRF S.A., reflexo de um problema de repercussão internacional, foi arquitetado para proporcionar o conhecimento acerca da governança corporativa e da teoria da Agência em meio a um problema de governança na BRF. O caso permite a análise da efetividade do Conselho de Administração como mecanismo interno de governança, a assimetria de informações, conflitos de interesse e a estrutura de propriedade.

A tomada de decisão deve ser embasada em dois pontos de vista: o da empresa e o do acionista. Pelo lado da empresa, observa-se o Conselho de Administração como mecanismo interno de Governança Corporativa. Sua eficiência na monitoria e sua composição deveriam ajudar um investidor a definir as melhores empresas para investimento, ainda que em um cenário em que sãoencontradosgrandes esquemas de lavagem de dinheiro, pagamento de propina e o acúmulo de notícias sobre má gestão. 
E do ponto de vista do acionista, observa-se um investidor que confiou suas reservas de capital àquela companhia, ao definir o retorno esperado e escolher apropriadamente os tipos de investimentos que deverão compor sua carteira. A ênfase didática é voltada a finanças, em que o risco é soberano. Uma escolha possível é o investimento em ações, embora estas continuem a ser vistas como uma caixa preta. Como escolher a empresa correta? Quais indicadores devem ser analisados? Quais características da empresa deveriam ser consideradas? As respostas são muitas e, ainda assim, não são definitivas.

O tema central da aplicação do caso diz respeito à Governança Corporativa. Dividimos esse tema em três eixos de conteúdos programáticos: teoria da Agência, Conselho de Administração e Estrutura de Propriedade. Os alunos são convidados a se colocarem no lugar, por um lado, do presidente do Conselho de Administração de uma companhia global e, por outro lado, de um acionista dessa companhia.

Antes da discussão do caso, recomenda-se a leitura integral das fontes dos dados e das obras referenciadas. Por meio da discussão do caso, especialmente com o debate das questões propostas, espera-se que os participantes possam: identificar passagens de conflito dos agentes e sugerir mecanismos que possam mitigar este problema; julgar o conselho de administração da BRF, por meio de suas características, tais como, a independência do conselho para a real efetividade do órgão de governança; e relacionar a composição acionária com o problema de gestão e suas consequências para investidores, especialmente para Marcelo, um investidor minoritário.

O caso busca ainda a compreensão histórica dos acadêmicos quanto a outros casos de problemas de efetividade do Conselho de Administração, que também possam ter impactado nos investidores minoritários, contextualizando a discussão do tema em outro tempo e outro cenário.

As questões apresentadas a seguir podem ser utilizadas com o objetivo educacional de discutir os eixos temáticos, por completo ou em separado, de acordo com a necessidade da aplicação.

\section{Questões sobre teoria da Agência}

a. Um dos princípios da teoria da Agência é a ideia de que os agentes podem ter informações assimétricas, o que potencializa conflitos entre as partes. Identifique passagens ou situações do caso em que isso possa ter ocorrido.

b. Outro princípio da teoria da Agência é a ideia de que os agentes podem ter interesses diferentes dos principais, ou seja, dos proprietários. Identifique passagens ou situações em que isso possa ter ocorrido no caso da BRF.

c. Cite possíveis mecanismos que poderiam diminuir os problemas acima, existentes no caso ou outros de sua sugestão.

\section{Questões sobre Conselho de Administração}

a. Quais são as características gerais do conselho da BRF?

b. Quais são as vantagens ou desvantagens de um presidente independente no conselho de administração?

c. E membros independentes? Auxiliam, ou não, nas práticas da boa governança? Se sim, como?

d. Como as características do conselho, a presença de um presidente e membros independentes, ajudaram ou não na revalorização da BRF?

\section{Questões sobre Estrutura de Propriedade}

a. Quais são as principais características da composição de propriedade da BRF?

b. Como pode ser relacionada a dispersão de propriedade com o problema de gestão do caso?

c. Qual a principal reação dos sócios estrangeiros com a queda no valor das ações provocada por um problema de corrupção?

d. Como o investidor minoritário Marcelo poderia mitigar o risco em curto período? 


\subsection{Aplicação do caso}

O caso para ensino apresentado pode ser utilizado para discussão em cursos de pós-graduação, especialmente em disciplinas cujos conteúdos se relacionem com Mercado de Capitais, Mercado Financeiro, Estratégia Empresarial e Governança Corporativa, mais especificamente na abordagem sobre mecanismos internos de Governança Corporativa e Teoria da Agência. Em turmas de graduação, recomenda-se aplicar o caso para alunos que estejam mais ao final de cursos de Administração, Contabilidade, Gestão e que estejam familiarizados com temas de Governança, Mercado Financeiro e Estratégia.

Para auxiliar o professor na melhor escolha do público, da disposição em sala, das seções de apresentação do caso, entre outras ações, sugere-se a leitura e análise da escala de níveis de dificuldade. O caso apresenta níveis de dificuldade 3, 3 e 1 na escala proposta por Leenders, Mauffette-Leenders e Erskine (2001), respectivamente para as dimensões analítica, conceitual e de apresentação, em que 1 significa fácil, 2 significa regular, e 3 significa difícil. Dividido em dimensão, nível, disposição no caso, explicação do nível de dificuldade e finalidade, conforme apresentado abaixo no Quadro 2:

\begin{tabular}{|c|c|c|c|c|}
\hline Dimensão & Nível & Disposição no caso & $\begin{array}{l}\text { Explicação do nível de } \\
\text { dificuldade }\end{array}$ & Finalidade \\
\hline Analítica & 3 & $\begin{array}{l}\text { São apresentados, no } \\
\text { caso, os critérios para } \\
\text { decisão na forma do } \\
\text { fato ocorrido, a forma } \\
\text { de tratamento até o } \\
\text { momento, pelas duas } \\
\text { partes, e a incógnita } \\
\text { sobre quais ações tomar } \\
\text { a fim de satisfazer às } \\
\text { duas partes. }\end{array}$ & $\begin{array}{l}\text { No caso não há desfecho. O } \\
\text { dilema para o aluno é o de se } \\
\text { colocar no lugar do presidente } \\
\text { do conselho da companhia e } \\
\text { como um dos acionistas. São } \\
\text { várias as possíveis decisões, } \\
\text { e uma ação da companhia } \\
\text { pode influenciar na decisão do } \\
\text { investidor. }\end{array}$ & $\begin{array}{l}\text { Nesta dimensão, a tarefa do } \\
\text { leitor do caso é relacionada à } \\
\text { decisão-chave do caso. A tarefa } \\
\text { analítica depende de como a } \\
\text { decisão é apresentada no caso: } \\
\text { com a alternativa escolhida, } \\
\text { alternativas sugeridas ou então o } \\
\text { leitor deve se colocar no contexto } \\
\text { para definir a melhor ação. }\end{array}$ \\
\hline Conceitual & 3 & $\begin{array}{l}\text { São delimitados três } \\
\text { eixos temáticos para a } \\
\text { conceituação individual. } \\
\text { A perspectiva teórica é } \\
\text { necessária para dirigir a } \\
\text { ação após o dilema. }\end{array}$ & $\begin{array}{l}\text { Há mais de um conceito } \\
\text { presente e estesexigem a } \\
\text { discussão e explicação e } \\
\text { explanação em sala de aula, } \\
\text { combinando-os com exemplos, } \\
\text { problemas ou exercícios, } \\
\text { principalmente quanto à } \\
\text { governança corporativa. }\end{array}$ & $\begin{array}{l}\text { A preocupação neste nível é } \\
\text { com quais teorias, conceitos } \\
\text { ou técnicas podem ser úteis na } \\
\text { compreensão e/ou resolução da } \\
\text { situação no caso. Considera-se } \\
\text { a dificuldade da própria teoria e } \\
\text { o número de conceitos a serem } \\
\text { usados simultaneamente. }\end{array}$ \\
\hline Apresentação & 1 & $\begin{array}{l}\text { As informações são } \\
\text { apresentadas numa } \\
\text { linguagem popular e o } \\
\text { enredo é envolvente. }\end{array}$ & $\begin{array}{l}\text { O caso conta com várias } \\
\text { inserções da mídia, o que } \\
\text { contribui para uma leitura fácil, } \\
\text { organizada e rapidamente } \\
\text { assimilada. Informações } \\
\text { teóricas e técnicas estão } \\
\text { restritas às notas de ensino. }\end{array}$ & $\begin{array}{l}\text { Fornece uma oportunidade para } \\
\text { desenvolver habilidades durante } \\
\text { a leitura e estruturar informações. } \\
\text { Envolve o leitor do início ao fim. } \\
\text { Caso curto, organizado, com } \\
\text { toda a informação relevante, de } \\
\text { forma simples e sem informações } \\
\text { estranhas. }\end{array}$ \\
\hline
\end{tabular}

Quadro 2. Níveis de dificuldade do caso

Fonte: elaboração própria, com base nos critérios propostos por Leenderset al. (2001, p. 17).

Como apoio ao professor, na aplicação do caso em sala de aula, sugere-se o roteiro a seguir. É importante garantir que os estudantes leiam com atenção o caso antes da aula. Se isso não for possível, pode-se reservar um tempo de 20 minutos, no início da sessão, para que os alunos façam a leitura em sala. 


\begin{tabular}{|c|c|c|}
\hline $\begin{array}{l}\text { Tempo } \\
\text { Estimado }\end{array}$ & Atividade & $\begin{array}{l}\text { Conceitos } \\
\text { Mobilizados }\end{array}$ \\
\hline $0-15 \min$ & Apresentação geral do caso, detalhando seus objetivos & Objetivos \\
\hline $30-40 \mathrm{~min}$ & $\begin{array}{l}\text { Discussão sobre as consequências,contextualizar o } \\
\text { ocorrido para a empresa. }\end{array}$ & $\begin{array}{l}\text { Contexto do ocorrido com a situação } \\
\text { político-econômica do País, bem como sua } \\
\text { repercussão internacional. }\end{array}$ \\
\hline $60-90 \mathrm{~min}$ & $\begin{array}{l}\text { 1. Sugestão: Formação de minigrupos. Distribuição dos } \\
\text { eixos temáticos (apresentados adiante) e levantamento } \\
\text { de soluções ou alternativas para estancamento dos } \\
\text { problemas. } \\
\text { 2. Sugestão: Discussão entre } 2 \text { grupos com } \\
\text { representantes, um no papel da empresa, e outro do } \\
\text { investidor. } \\
\text { 3. Sugestão: Criação de grupos múltiplos de 2, em que } \\
\text { metade fica responsável por responder as questões } \\
\text { com afirmações positivas, e a outra parte responde de } \\
\text { forma contrária. }\end{array}$ & $\begin{array}{l}\text { - Governança Corporativa } \\
\text { - Teoria da agência } \\
\text { - Conselho de administração } \\
\text { - Estrutura de propriedade }\end{array}$ \\
\hline 20-30min & $\begin{array}{l}\text { Fechamento da aula com as devidas tomadas de decisão a } \\
\text { partir de então. }\end{array}$ & $\begin{array}{l}\text { Decisões da companhia perante o caso, a } \\
\text { curto, médio e longo prazo }\end{array}$ \\
\hline
\end{tabular}

Quadro 3. Plano de aula sugerido

Fonte: os autores.

\subsection{Propostas de encaminhamento para as questões}

1.

a) O caso apresenta problema causado devido a informações assimétricas,em que o Conselho de Administração não sabia da prática corrupta de pagamento de propina a fiscais do Ministério da Agricultura para conseguir a emissão de certificados de qualidade. Para Jensen (1993), problemas sérios de informação limitam a eficácia dos membros do Conselho nas grandes corporações. Por exemplo, o CEO quase sempre determina a agenda e as informações dadas ao Conselho. Essa limitação da informação prejudica gravemente inclusive a capacidade de membros talentosos da Diretoria contribuírem eficazmente para o monitoramento e avaliação do CEO e da estratégia da empresa.

b) Houve conflito de interesses no caso, uma vez que o Conselho de Administração (agentes) não representou de fato os interesses dos acionistas (principais), pela sua falta de efetividade em formular, dirigir e controlar as políticas, diretrizes e estratégias. As informações expostas mostram que o Conselho sequer sabia da prática ilegal, deixando assim de resolver internamente o problema de pagamento de propina. Wiseman e Barton (2015) afirmam que um bom primeiro passo seria todos entenderem perfeitamente o que significa "obrigação fiduciária" de um conselheiro. A maioria dos códigos legais destaca dois aspectos fundamentais: fidelidade (colocar os interesses da empresa acima de qualquer outro) e prudência (dispensar atenção, habilidades e diligência adequadas às decisões dos negócios). O papel de um conselheiro leal e prudente não é forçar o executivo a maximizar valor aos acionistas no curto prazo, em detrimento de qualquer outro interesse. Ao contrário, é que o conselheiro deve ajudar a empresa a ter sucesso por anos a fio.

c) A mídia atuou como mecanismo externo de governança, ativando o Conselho de Administração, mecanismo interno, para a irregularidade que havia na companhia, e trazendo à tona a falta de efetividade deste órgão. Para Aguilera, Desender, Bednar e Lee (2015), a mídia é considerada mecanismo externo, pois pode amplamente divulgar informações. Ela existe para exercer um papel de controle, em que a ameaça, como imprensa negativa, pode impedir os gestores de agir de forma auto interessada, por medo de danos à sua reputação, além deagir na teoria de agência da governan- 
ça para aumentar a eficácia, aumentando a transparência e reduzindo a assimetria de informação. Com base no caso, a mídia, como um mecanismo externo de governança, ativou o Conselho de Administração para a ocorrência de uma prática de suborno, demonstrando, assim, a falha do mecanismo interno. Também a Polícia Federal atuou como mecanismo externo, por meio do sistema legal, ao deflagrar a Operação Carne Fraca. Ainda, segundo Aguilera et al. (2015), o sistema legal é o conjunto de estruturas e processos utilizados para interpretar e aplicar a lei existente. Estabelece como os direitos de propriedade são definidos e protegidos, e inclui instituições reguladoras, que supervisionam normas e regras que as firmas devem cumprir.

2 .

a) O Conselho é composto de nove membros, sendo seis independentes. O presidente do Conselho é um dos membros independentes. Por norma da BRF, o presidente do Conselho de Administração não exerce funções executivas. Não há dualidade no comando, sendo Pedro Faria o CEO e Abílio Diniz o presidente do Conselho. Também estão definidas, no Estatuto Social, que o presidente deve ter reputação ilibada, não ocupar cargos em concorrentes nem representar interesses conflitantes. Em sua grande maioria, os conselheiros são formados em Administração, Finanças ou Economia.

b) Um presidente independente deve prezar muito pela sua reputação e atividade exercida na empresa, uma vez que ele pode estar sendo observado por outras companhias, para que faça parte futuramente do seu Conselho de Administração. Dessa forma, ele está muito mais preocupado com sua reputação, de forma a utilizar toda sua expertise para poder manter sua reputação perante todas as companhias. A CVM recomenda, entre as práticas de boa governança corporativa, que, devido ao fato de o Conselho de Administração ter a função de fiscalizar a gestão dos diretores, para evitar conflitos de interesses, o presidente do Conselho de Administração não deve ser também o presidente da Diretoria ou seu executivo principal. Conforme Fama e Jensen (1983), para proteger os fluxos de informação ao Conselho, espera-se que os altos executivos, especialmente aqueles que são membros do Conselho, possam efetivamente ser despedidos apenas com o consentimento do Conselho e, portanto, protegidos contra represálias de outros altos executivos. Os conselhos corporativos geralmente incluem membros externos, isto é, membros que não são gerentes internos, e que muitas vezes detêm a maioria dos assentos.

c) Pelo IBGC, os Conselhos de Administração de companhias do Novo Mercado deverão ser compostos por, no mínimo, 5 (cinco) membros, eleitos pela assembleia geral, dos quais, no mínimo, 20\% (vinte por cento) deverão ser conselheiros independentes. Os membros externos do conselho agem como árbitros em desacordos entre gerentes internos e executam tarefas que envolvem graves problemas de agência entre gerentes internos e reclamantes residuais, por exemplo, fixando remuneração de executivos ou procurando substituições para gerentes de topo. A separação efetiva entre o gerenciamento e o controle de decisões de alto nível significa que os diretores externos têm incentivos para realizar suas tarefas e não colidir com os gerentes, para expropriar os reclamantes residuais. A maioria dos diretores externos de corporações abertas é ou gerente de outras corporações ou importante agente de decisão em outras organizações complexas. $\mathrm{O}$ valor de seu capital humano depende principalmente de seu desempenho como gerente interno de decisão em outras organizações. Uma das recomendações da cartilha de governança corporativa da CVM também é que o conselho deve ter o maior número possível de membros independentes da administração da companhia.

d) Como observado na Figura 1, o valor das ações da BRF após um mês e um dia da deflagração da operação era de 40,62 reais, ultrapassando até mesmo o valor anterior ao do dia do anúncio da Operação Carne Fraca e também da sua divulgação em massa pela mídia. Essa recuperação se deve, principalmente, ao plano de ação elaborado na reunião entre conselho e CEO no dia 17 de março 
de 2017. Os conselheiros criaram um comitê de gestão da crise. Convocaram os principais criativos da agência de publicidade DM9, os diretores da agência de relações públicas Loures Comunicação, dos três escritórios de advocacia que dão suporte jurídico à empresa, e chamaram também os mais experientes diretores e funcionários de alto escalão da BRF. O caso retratou que o Conselho de Administração é pouco influente na descoberta de ilícitos, até pela visão de que é logicamente impossível saber-se de tudo. Contudo, um bom conselho consegue blindar o valor de mercado em longo prazo, como visto com as ações da BRF, que retornaram a valores até superiores após pouco mais de um mês da deflagração da investigação da PF.

3.

a) Conforme observa-se na Tabela 1, a composição de propriedade da BRF é dispersa, sendo o acionista com maior percentual a Tarpon, uma companhia gestora de investimentos, dona de 11,94\% das ações. Em seguida vem a Petros, Fundação Petrobras de Seguridade Social, com 11,42\%. A terceira maior acionista é a Previ, Caixa de Previdência dos Funcionários Banco do Brasil, com 10,65\%. Com 5,03\%, a BlackRock Inc. é a quarta maior acionista, companhia global Americana de Investimentos. A GIC Private Limited possui 5,01\% das ações da BRF, e é uma companhia de investimentos de Singapura. E 1,66\% das ações da BRF foram adquiridas pela própria companhia e assim nomeadas como Ações em Tesouraria. As 45,71\% das ações restantes estão em propriedade dos acionistas minoritários. Constata-se que há uma alta dispersão de propriedade, o que deve levar a um maior controle de governança e minimizar a interferência interna.

b) A dispersão acionária leva à premissa existente de que o controle difuso da companhia resulta em maior demanda por uma administração eficiente dos negócios. Minimiza a interferência interna, aumentando a independência, e gera mais governança. No caso, o problema de gestão ocorreu mesmo havendo alta dispersão de propriedade. Essa característica exige uma maior eficiência da administração. O regulamento do segmento de Novo Mercado da Bolsa Brasileira faz menção à dispersão acionária, de forma que, em toda e qualquer oferta pública de distribuição de ações, a Companhia deverá envidar melhores esforços com o fim de alcançar dispersão acionária, com adoção de procedimentos especiais, os quais constarão no respectivo prospecto, como por exemplo: a) garantia de acesso a todos os investidores interessados; ou b) distribuição a pessoas físicas ou investidores não institucionais de, no mínimo, $10 \%$ (dez por cento) do total a ser distribuído (BM\&FBOVESPA, 2011). No caso da BRF, existe uma concentração de grandes fundos gerindo a BRF, embora não sejam majoritários (com mais de $50 \%$ das ações) e que gerem ativamente as decisões da BRF, inclusive com conselheiros nomeados pelos próprios fundos. Dispersão é bom, mas com limite. A partir desse limite, haverá muitos acionistas que desejarão agir ativamente na empresa. Jensen e Meckling (2008) afirmam que é provável que a maioria dos conflitos mais importantes seja proveniente do fato de que, à medida que o direito pela propriedade do administrador diminui, o seu incentivo a dedicar um esforço relevante a atividades criativas, como buscar novos empreendimentos lucrativos, também diminui. Ele pode, na verdade, evitar esses empreendimentos simplesmente porque implicariam muita preocupação ou esforço de sua parte para administrá-los ou aprender novas tecnologias. Concluindo,dessa forma, que a concentração de propriedade é benéfica para as corporações, pois pode gerar menores custos e o monitoramento da administração fica mais eficiente.

c) Acionistas estrangeiros procuraram um escritório de advocacia norte-americano o qual está preparando processos coletivos para recuperar perdas sofridas pelos acionistas. Segundo a matéria da Época Negócios (2017), a Rosen Law Firm está investigando potenciais acusações em nome de acionistas, que resultam de alegações de que a JBS pode ter emitido informações materialmente enganosas de negócios ao público investidor. Essa reação remete parcialmente ao caso da Enron, nos 
Estados Unidos, quando executivos manipularam os balanços contábeis, com a ajuda de empresas e bancos, e com isso esconderam dívidas de 25 bilhões de dólares por dois anos consecutivos, tendo inflado artificialmente os lucros da companhia.

d) Em primeiro lugar, em finanças, um conceito importante para a mitigação de riscos é o uso da diversificação dos ativos. Ao comprar ações (por exemplo) de empresas cujas oscilações de mercado são não correlacionadas, Marcelo poderia evitar que grandes quedas de mercado o atingissem. Caso sua decisão, ainda assim, fosse a de investir em apenas uma empresa, Marcelo cumpriu boa parte de seu dever de casa, ao investir em uma empresa com boas práticas de governança corporativa, tendo membros capacitados e independentes no Conselho de Administração, propriedade dispersa, entre outras características. Uma última estratégia para Marcelo poderia ter sido a de lotes menores e gradativos de investimentos, como a compra ou venda parcial de suas ações de acordo com o andamento de mercado.

\section{Fechamento}

Uma alternativa para o encerramento da discussão em plenário poderia ser a proposição de uma situação desafiadora: levantar outro possível tratamento que a companhia poderia ter dado ao ocorrido e à sua repercussão. Também, por parte do acionista, encontrar as melhores atitudes, colocando-se no lugar dele, diante do seu investimento em ações da BRF.

Um caso para ensino não é um exercício, não há respostas certas, há as melhores respostas, que podem levar a uma melhor decisão. Sugere-se encerrar o caso com uma questão aberta: quais outros casos de corrupção corporativa podem ser citados, a exemplo do que aconteceu com a BRF? Com essa questão, pretende-se instigar os alunos a pensar mais sobre o tema, transportando a discussão do caso de forma externa à sala de aula. O propósito é deixar uma lição importante do entendimento de como falhas na governança corporativa de empresas podem levar a perdas de valores substanciais. Além do ilustrado pela BRF, assim como por outras empresas de projeção internacional, como a Enron, e as brasileiras Sadia, Aracruz e OGX.

\section{Referências utilizadas e recomendadas}

Aguilera, R. V., Desender, K., Bednar, M. K. \& Lee, J. H. (2015). Connecting the Dots: Bringing External Corporate Governance into the Corporate Governance Puzzle, The Academy of Management Annals, 9(1), pp. 483-573, doi: http://dx.doi.org/10.1080/19416520.2015.1024503

Bonin, R. (2017, março, 29). O custo Brasil sujo. Revista Veja, 2523(13), Ano 50, pp. 54-55.

Bonin, R., \& Alvarenga, B. (2017, março, 29). A carne nem é fraca, mas o estrago é forte. Revista Veja, 2523(13), Ano 50, pp. 46-49.

BRF. (2017). Estatuto Social BRF. Recuperado em 22 de abril, 2017 de http://ri.brf-global.com.

Caetano, M. (2017, abril). Os limites da inspeção. Revista Dinheiro Rural, 146, pp. 32-34.

Campbell, U. (2017, março, 29). Errou na mosca. Revista Veja, 2523(13), Ano 50 pp. 50-51.

Cilo, H. \&Drska, M. (2017, março, 29). O contra-ataque de BRF e JBS. Revista Isto É Dinheiro, 1011, pp. 42-46.

Comissão de Valores Mobiliários (2002). Cartilha de boas práticas de governança corporativa. Recuperado em 22 de abril, 2017 de http://www.cvm.gov.br. 
Fama, E. F. \& Jensen, M. C. (1983). Separation of Ownership and Control, The Journal of Law and Economics, 26(2), pp. 301-325, doi: http://dx.doi.org/10.1086/467037

Filgueiras, M. L. (2017, março, 29). Mudar tudo. De novo. Revista Exame, 1134(6), Ano 51, pp. 76-88.

Gradilone, C. (2017, março, 29). Repercussões da operação Carne Fraca no exterior podem dificultar avenida de ações da BRF e da JBS no mercado internacional. Revista Isto É Dinheiro, 1011, pp. 48-49.

Instituto Brasileiro de Governança Corporativa (IBGC) (2015). Código das melhores práticas de governança corporativa. ( $5^{\mathrm{a}}$ ed.), 108 São Paulo.

Instituto Brasileiro de Governança Corporativa (IBGC). (2007).Guia de orientação para o gerenciamento de riscos corporativos, 48 . São Paulo,

Jensen, M. (1993). The modern industrial revolution, exit, and the failure of internal control systems. The Journal of Finance, 48(3), pp. 831-880, doi: http://dx.doi.org/10.2139/ssrn.93988

Jensen, M.C.\&Meckling, W.H. (2008). Teoria da firma: comportamento dos administradores, custos de agência e estruturas de propriedade. RAE-Clássicos, 48(2), pp. 87-124.

Leenders, M. R.,Mauffette-Leenders, L. A.\&Erskine, J. A. (2001). Writing cases. (Fourth Edition). Ontario: Richard Ivey School of Business.

Wiseman, M. \&Barton, D. Ondeosconselhosfalham. Harvard Business Review Brasil. Jan, 2015. Recuperado em 22deabril, 2017 de http://hbrbr.uol.com.br/onde-os-conselhos-falham/.

\section{Referências recomendadas}

Daily, C. M., Dalton, D. R. \& Cannella, A. A. (2003). Corporate governance: Decades of dialogue and data. Academy of Management Review, 28(3), pp. 371-382, doi: http://dx.doi.org/10.2307/30040727.

Denis, D. K. \&Mcconell, J. J. (2003). International corporate governance.Journal of Financial and Quantitative Analysis, 38(1), pp. 1-36, doi: http://dx.doi.org/10.2307/4126762

Freitas R. M. de N. \& Mol, A. L. R. (2017, April). Determinantes dos papéis dos Conselhos de Administração de Empresas Brasileiras. RAC, Rio de Janeiro (sai), 21(spe), pp. 63-83, doi: http://dx.doi. org/10.1590/1982-7849rac2017160053

Silveira, A. D. M. da (2005). Governança corporativa: desempenho e o valor da empresa no Brasil. São Paulo: Saint Paul Editora.

Silveira, A. D. M. da (2010). Governança corporativa no Brasil e no mundo: teoria e prática. Rio de Janeiro: Elsevier.

\section{Sites consultados}

ADVFN Brasil. Recuperado em 20 de abril, 2017 de http://br.advfn.com.

Infomoney (2017). A carne é fraca e a fé também: o mercado desistiu da BRF após mais uma má notícia? Recuperado 20 em abril, 2017 de http://www.infomoney.com.br.

Regulamento de listagem do novo mercado (2011). BM\&FBOVESPA. Recuperado em 01 de maio, 2017 de http://www.bmfbovespa.com.br.

Carta Capital (2017). Carne Fraca: O que pesa contra a BRF e a JBS. Recuperado em 20 de abril, 2017 de https://www.cartacapital.com.br. 
Época Negócios (2017). Escritório dos EUA prepara ações contra BRF e JBS após operação Carne Fraca. Recuperado em 30 de abril, 2017 de http://epocanegocios.globo.com.

Folha de São Paulo (2017). Operação contra frigoríficos prende 37 e descobre até carne podre à venda. Recuperado em 30 de abril, 2017 dehttp://www1.folha.uol.com.br/mercado/2017/03/1867309-pf-faz-operacao-contra-frigorificos-e-cumpre-quase-40-prisoes.shtml.

Globo Rural (2017). União Europeia pede reunião de emergência com o Brasil sobre fraude da carne. Recuperado em 20 de abril, 2017 de http://revistagloborural.globo.com.

UOL Economia (2017). Em escuta, diretor da BRF fala de bactéria, propina e exportação vetada. Recuperado em 22 de abril, 2017 de https://economia.uol.com.br/noticias/redacao/2017/03/25/em-escuta-diretor-da-brf-fala-de-bacteria-propina-e-exportacao-vetada.htm.

Website de Relação com Investidores BRF (2017) Governança Corporativa. Recuperado em 25 de março, 2017 de http://ri.brf-global.com.

Website B3 (2017). Recuperado em 22 de abril, 2017 de http://www.bmfbovespa.com.br.

Website EconoInfo (2017). Recuperado em 29 de março, 2017 de http://www.econoinfo.com.br. 